\title{
The information system for the regional energy balance formation
}

\author{
Roman Muzychuk ${ }^{*}$, Melentiev Energy Systems Institute of Siberian Branch of the Russian \\ Academy of Sciences, Irkutsk, Russia
}

\begin{abstract}
A study of the energy efficiency of the fuel and energy complex of the regions has a great attention. For an integrated introduction of trends and patterns in the energy sector, approaches we use based on the analysis of the fuel and energy balance (FEB). The function of FEB is to show the availability and use of energy resources in a certain territory and determination of indices of energy efficiency. The article presents an approach to the formation of fuel and energy balances based on the available statistical information.
\end{abstract}

\section{Introduction}

The growth of the energy efficiency of economy is one of the priorities of the socioeconomic development of the regions in the field of the fuel and energy complex. It also determines the relevance of research on the rationalization of the use and production of fuel and energy resources. Taking into account the development forecast of the fuel and energy complex the fuel and energy balance is a tool for a comprehensive assessment of the production and use of fuel and energy resources in the region. FEB connects production of all types of energy resources to their final consumption. The development of consolidated energy balances is the main method of systems analysis of the energy sector.

The study on the energy development on the energy balance in Russia was started in 1920-1930 (Krzhizhanovsky G.M., Veits V.I.), continued in 1950-1960 (Melentiev L.A., Styrikovich M.A.) and in 1970-1980 (Nekrasov A.S., Makarov A.A.). And later, (Bashmakov I.A., Bushuev V.V., Suslov N.I., Filippov S.P., and others).

Despite the approval of the order of the Ministry of Energy of the Russian Federation No. 600 on the procedure for compilation of fuel and energy balances, there are uncertainties in connection with the recurring information in statistics forms.

Computer modelling of the energy development using the information system (IS) are:

- collecting data of: external energy links of regions; energy consumption levels, given energy efficiency growth; primary energy production; energy resources transfer system; primary energy resources processing; final energy consumption;

- filling in intermediate forms;

- forming of one-product balances [1]: coal, other solid fuels, crude oil, oil products; natural gas; electricity and heat energy;

- interpretation and analysis of results.

\footnotetext{
*orresponding author: rmuz@isem.irk.ru
} 


\section{The primary balance formula and balance sheet form}

The fuel and energy balance is the quantitative correspondence of the incoming and outgoing part of the fuel and energy in the region. The incoming part is the sum of the extraction or production of energy resources and their import into the region. The outgoing part consists of the amounts determining the volumes of fuel consumption for the production of electricity and heat energy. As well as direct consumption, export of energy resources and an indicator of reserves and losses (1).

$$
P+I=\Sigma b_{j}{ }^{e} \cdot W_{j}+\Sigma b_{l}{ }^{h} \cdot Q_{l}+A+E+L
$$

$P$ - extraction (production) of energy resources in the region;

$I$ - energy resource import into the region;

$j$ - energy source type index for power generation;

$b_{j}{ }^{e}$ - specific energy consumption for electricity generation;

$W_{j}$ - power generation;

$l$ - energy source type index for a heat generation;

$b_{l}{ }^{h}-$ specific energy consumption for a heat generation;

$Q_{l}$ - heat production;

$A$ - final energy demand;

$E$ - energy exports from the region;

$L-$ accumulation and loss indicator.

The form of the table of fuel and energy balance (Fig. 1) is divided into 3 main parts. Resource part includes the production of primary energy resources, exports, imports (import-export for regions) and changes in stocks. Fuel conversion part determines the fuel balance of heat and electricity production, the scale of total consumption and production of electric and thermal energy, as well as the size of energy losses during their production. The consumption of fuel and energy by sectors of the economy is in the final consumption part. Negative values show fuel and energy consumption. Positive values show the production of converted energy carriers. In the header of the table are the types of fuel and energy.

\begin{tabular}{|c|c|c|c|c|c|c|c|c|c|c|c|}
\hline & & Coal & $\begin{array}{c}\text { Crude } \\
\text { Oil }\end{array}$ & $\begin{array}{c}\text { Oil } \\
\text { products }\end{array}$ & $\begin{array}{c}\text { Natural } \\
\text { Gas }\end{array}$ & Other & $\begin{array}{l}\text { Hidro and } \\
\text { renewables }\end{array}$ & Nuclear & $\begin{array}{l}\text { Electri- } \\
\text { city }\end{array}$ & Heat & Total \\
\hline & & 1 & 2 & 3 & 4 & 5 & 6 & 7 & 8 & 9 & 10 \\
\hline Energy production & 1 & E11 & E12 & E13 & E14 & E15 & E16 & E17 & & & E110 \\
\hline Export & 3 & $-E 31$ & $-E 32$ & $-E 33$ & $-E 34$ & & & & $-E 38$ & & E310 \\
\hline Stock change & 4 & E41 & E42 & $E 43$ & E44 & & & & & & E410 \\
\hline Primary energy consumption & 5 & E51 & E52 & E53 & E54 & E55 & E56 & E57 & E58 & & E510 \\
\hline Heat production & 8 & $-E 81$ & $-E 82$ & $-E 83$ & $-E 84$ & $-E 85$ & $-E 86$ & $-E 87$ & E88 & E89 & E810 \\
\hline Thermal Power Plants & 8.1 & $-E 811$ & $-E 821$ & $-E 831$ & $-E 841$ & $-E 851$ & & & E881 & E891 & E8101 \\
\hline Boiler Plants & 8.2 & $-E 812$ & $-E 822$ & $-E 832$ & $-E 842$ & $-E 852$ & & & E882 & E892 & E8102 \\
\hline Electric Boiler plants & 8.3 & & & & & & & & $E 883$ & E893 & E8103 \\
\hline Fuel conversion & 9 & -E91 & -E92 & -E93 & -E94 & -E95 & & & -E981 & E99 & E910 \\
\hline Oil refining & 9.1 & $-E 911$ & $-E 921$ & $-E 931$ & -E941 & -E951 & & & $-E 981$ & E991 & E9101 \\
\hline Final consumption & 12 & E121 & E122 & E123 & E124 & E125 & & & E128 & E129 & E1210 \\
\hline Agriculture & 13 & E131 & $\mathrm{E} 132$ & E133 & E134 & E135 & & & E138 & E139 & E1310 \\
\hline Industry & 14 & E141 & E142 & E143 & E144 & E145 & & & E148 & E149 & E1410 \\
\hline Building & 15 & E151 & E152 & E153 & E154 & E155 & & & E158 & E159 & E1510 \\
\hline Transport and communication & 16 & E161 & E162 & E163 & E164 & E165 & & & E168 & E169 & E1610 \\
\hline Services & 17 & E171 & E172 & E173 & E174 & E175 & & & E178 & E179 & E1710 \\
\hline Residental & 18 & E181 & E182 & E183 & E184 & E185 & & & E188 & E189 & E1810 \\
\hline $\begin{array}{l}\text { Raw materials and for non-fuel } \\
\text { needs }\end{array}$ & 19 & E191 & E192 & E193 & E194 & E195 & & & E198 & E199 & E1910 \\
\hline
\end{tabular}

Fig. 1. Common fuel and energy balance table form to fill. 


\section{Data processing approach}

The main difficulties of analysing the current state and forecasting the development of the fuel and energy complex at the stage of collecting statistical information and systematically tracking it for further use in prospective studies are:

- large amount of information that must be considered when forecasting;

- presence of various types of sources in which the same information can be represented by different quantities;

- bringing information received from various sources into a single form, adapted for further use.

There a significant number of documents using to describe the fuel and energy complex of the region. They has various extensions that cannot be used to automate the process of compiling balances without additional labour-intensive processing. In common it is statistical information, both in the forms of state reporting and in the forms of statistical reporting of various enterprises in the region. Differences in formats make it difficult for a specialist in the field of fuel and energy to use this electronic information and necessitate converting it into a convenient form for work, for example, in the form of MS Excel tables. Thus, the availability of a reliable and convenient tool that allows you to use all the necessary information and carry out calculations using this tool is a prerequisite for research on compiling promising energy balances and forecasting the development of the fuel and energy complex. As such a tool, the Information System is proposed, which will eliminate the above difficulties.

The results of many years of material development for the compilation of balances, forecasts and reports, accumulated a significant amount of processed information, and also determined the approach to data structuring. The integrated scheme of data and dependencies in the information system is presented in Fig. 2.

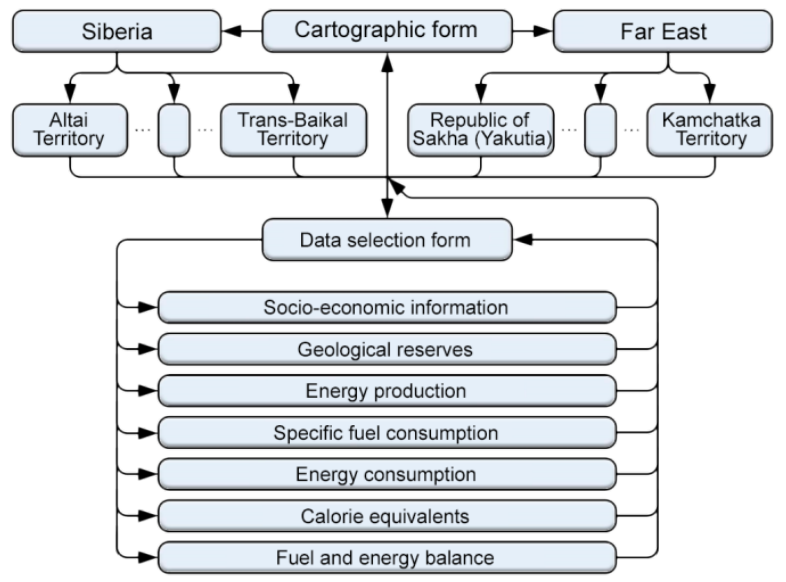

Fig. 2. The scheme for modelling the energy balance in the eastern regions of Russia.

The system consists of two working files Siberia.xls and FarEast.xls, which are combined with macros and forms MS Visual Basic for Applications. Each sheet in the books corresponds to its own region (subject of the Russian Federation). The location of information on MS Excel sheets for any region is given statically; therefore, aggregation of information by large regions, in our case, Eastern Siberia and the Far East, in most cases, is reduced to summing up the corresponding indicators of the constituent entities of the Russian Federation of the components of the large region. The type of information arrangement in the ISC allows to take full advantage of the system of models created in the 
department of regional energy problems of the Institute of Energy Systems of the SB RAS and presented in the monograph "Methods and models for the development of regional energy programs" [2].

\section{Data base filling sources}

The full functioning of any software package is impossible without the constant updating of databases. It is necessary to maintain and supplement the databases of constantly used statistical forms of state reporting. Like these: electrical balance forms; "6TP" (production of electric and thermal energy and the use of fuel in the power industry); "11-TER" (use of fuel, heat energy and electricity); "4-TER" (information on the residues, the receipt and fuel consumption, the collection and use of waste oil); production of the most important types of industrial products, etc. In addition, take into account: data on the production and conversion of certain types of energy carriers; data of enterprise surveys, various reports, media information, etc. Often, different sources contain conflicting information. The FEB filling process, shown in Fig. 3, helps to fill in some data automatically according to the rules. The accumulation of information on the object allows screening out unreliable data (expertly).

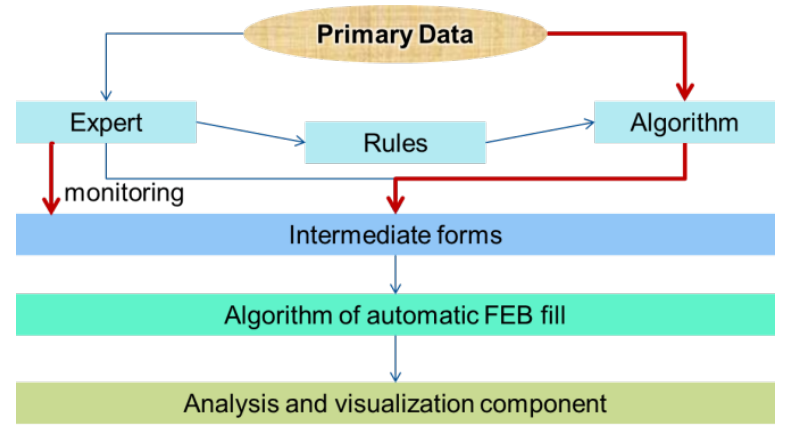

Fig. 3. FEB filling automation.

The IS has a territorial-sectoral principle, for regions with the separation of industries (figure 4) (coal, gas, oil, gas and oil refining, etc.) and have a block structure: the production of fuel and energy resources, their energy and final consumption, and supplies. This structure allows automating the compilation of the FEB of the region, and combine information up to federal districts. The use of IS helps in other studies [3].

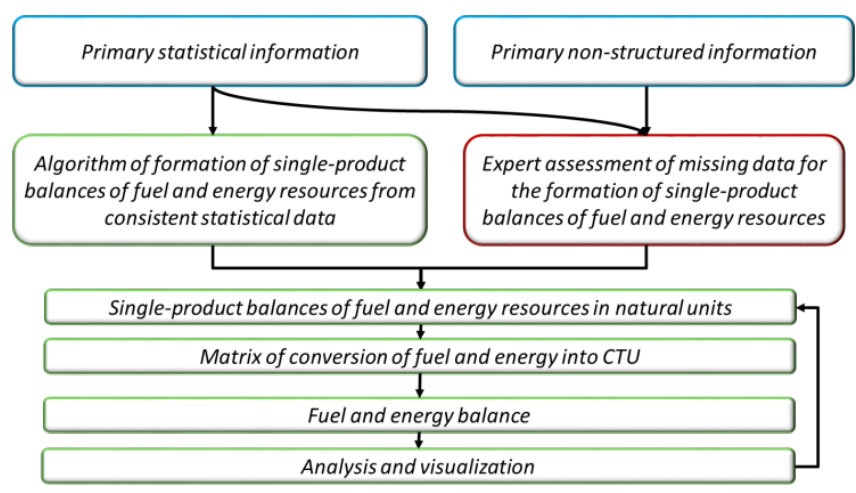

Fig. 4. Algorithm of getting a consolidated FEB. 


\section{Conclusion}

The proposed information system, as a decision support system, provides an interface to access data that are presented in a form defined by the user and convenient for analysis (tables, graphs, charts). I.e. IS is a toolkit for the preparation and provision of the most complete and interconnected information for an expert in order to determine quantitative indicators of a thermopile and, if possible, fill out a fuel and energy table according to predetermined rules.

\section{Acknowledgements}

Research was supported by XI.174.2.2. рег. №AAAA-A17-117030310435-0

\section{References}

1. I.A. Bashmakov. Energy policy. Fuel and energy balance as a tool for analysis, forecasting and indicative planning of energy development, 2, pp.16-25. (2007).

2. B.G. Saneev, A.D. Sokolov, G.V. Agafonov. Methods and models for the development of regional energy programs. Novosibirsk: Science. 140p. (2003).

3. B.G. Saneev, A.D. Sokolov, S.Yu. Muzychuk, R.I. Muzychuk. Bulletin of the Russian Academy of Sciences. Energy. Fuel and energy balances in the system of complex studies of the development of the regional energy industry, 2, pp. 21-35. (2011). 